Open Access

\title{
Strategies to promote Chinese international students' school performance: resolving the challenges in American higher education
}

\author{
Dongfang Liu
}

Correspondence:

dongfang.liu@unco.edu

University of Northern Colorado,

McKee 418/CB 103, 501 20th Street,

Greeley, CO 80639, USA

\begin{abstract}
In recent years, there has been an increase in Chinese international students attending American universities. Chinese international students in American higher education represent the largest group of international students from a single country. However, research and media reports have documented that Chinese students in America are now facing a variety of difficulties in their education in America. In this regard, this study aims to track Chinese international student progress and further identify supports that may increase their academic success at American universities and colleges. Informed by the voices and experiences of participants, the findings from the study demonstrate that the Chinese international students who are currently attending American higher education are facing difficulties in language proficiency, emotional issues, and American pedagogy. Based on the findings, the author has provided recommendations to increase Chinese international students' academic success in American institutions of higher education.
\end{abstract}

Keywords: American higher education, Chinese international students, International preparation program, Language learning for academic purpose, Education leadership

\section{Introduction}

Chinese students have been coming to the United States since Nixon's visit to China in increasing numbers (Chu 2004). Seven years after President Nixon visited China and three decades after the founding of the People's Republic, the United States and the People's Republic of China announced diplomatic relations on January 1, 1979 (Chu 2004). Fifty Chinese students arrived in America to further their studies five days before diplomatic ties were established, and by 2003, there were more than 580,000 Chinese students who had gone abroad to study, the majority of them to America (Chu 2004).

From 2000 to 2012, there has been an increase in Chinese international students attending American universities (Ruiz 2014). That trend is consistent with the booming Chinese economy, which allows more and more Chinese families to save enough money to send their children to America for an education (Ruiz 2014). In 2013, international students contributed approximately $\$ 21.8$ billion in tuition and $\$ 12.8$ billion in other expenditures to the American economy (Ruiz 2013). Among the international

(c) 2016 The Author(s). Open Access This article is distributed under the terms of the Creative Commons Attribution 4.0 International License (http://creativecommons.org/licenses/by/4.0/), which permits unrestricted use, distribution, and reproduction in any medium, provided you give appropriate credit to the original author(s) and the source, provide a link to the Creative Commons license, and indicate if changes were made. 
students flocking into America higher education, nearly 200,000 of them are from China, which represents the largest group of international students from a single country and accounts for $25.4 \%$ of all foreign students studying in the U.S (Zhao 2013).

Traditionally, Chinese students did well in the American education system. Kaufman (2004) reported that first generation Chinese immigrants perceived success in school as mainly dependent on their personal efforts, rather than social environment. These first generation Chinese immigrants demonstrated high motivation when faced with challenging curriculum and valued demanding teachers (Kaufman 2004; Zhou et al. 2003). Furthermore, Chinese parents actively engaged in their children's education and tended to invest in a variety of supports to facilitate their children's educational success (Siu 1994).

However, research and media reports have documented that Chinese students in America are now facing a variety of difficulties in their education in America (FlorCruz 2013; Liu et al. 2014; Luo 2013). Even the students with outstanding academic achievements in Chinese high schools are struggling in American colleges (Liu et al. 2014). For instance, Liu et al. (2014) found that Chinese students' high school GPA and standardized test scores are not consistent with their American university performance, because Chinese international students lack systematic preparation for academic transition in American higher education. Another report about Chinese students' poor performance in American colleges attracted widespread anxiety in Chinese society (Luo 2013). This report revealed that there was a surprisingly high dropout rate for Chinese international students studying in Ivy League schools, which only admit exceptionally achieving students (Luo 2013). This news shocked Chinese society where parents and educators primarily focus on helping students to attain high test scores for admission to the next level of education. Luo (2013) identified differences in language and the education system between China and the Western world that were barriers to some Chinese students' academic performance, increasing the likelihood that they would not complete their degree programs. These findings were supported by the work of FlorCruz (2013), as well. Liu (2013) found that an increasing number of Chinese students were expelled because of cheating, and Harris (2012) also found that cheating, lying to get admitted, low levels of class involvement, and self-segregation were all factors in Chinese students' lack of success in American universities.

Attending an American university for higher education is a costly venture for Chinese families. More than $60 \%$ of Chinese families privately fund their children's education in America without financial aid. Most Chinese students spend an average of $\$ 200,000$ just for tuition and fees over four years (Zhao 2013). Accommodations for Chinese students attending American universities cost $\$ 12.8$ billion according to Ruiz (2013). There are also additional costs often accrued before students are ever admitted to an American university. Before applying to American universities, Chinese students have to spend thousands of dollars on TOEFL and SAT classes, international high schools for American curriculum, and round-trip flights to take the Scholastic Aptitude Test (SAT), which is not administered in Mainland China (Zhao 2013). These costly investments, however, often do not benefit students as anticipated.

A large proportion of Chinese international graduates struggle to find employment in America and end up moving back to China (FlorCruz 2013). FlorCruz claimed that, after examining more than 9000 Chinese students in 23 major American cities, a large proportion of respondents noted that, due to the extremely competitive employment 
markets in America, they preferred to return to China (FlorCruz 2013). However, Chinese international students receiving American degrees are also having a difficult time finding employment in China (Zhao 2013). More than $70 \%$ of employers would not give preferential treatment to "hai gui" (the Chinese name for Chinese international graduates), and almost $8 \%$ say they actually prefer not to hire "hai gui" because of poor academic performance in school and poor social skills (Zhao 2013).

In considering the inconsistent or poor academic performance of Chinese international students, difficulty integrating into American society, increased dropout rates, and most importantly, difficulty finding employment due to mismatched skills in both countries, it is likely that Chinese enrollment in American universities may not continue to increase. As the first generation of American-educated Chinese international students return to China and are not as successful as they had anticipated, there will likely be a plateau of Chinese international students applying to the United States in the near future (Fischer 2014). This will have financial implications for American universities as the approximately $\$ 33$ billion in tuition and accommodation currently spent by Chinese students attending America universities decreases (Zhao 2013).

It would be a benefit to both America and China to work together to better prepare Chinese international students to be more successful in American universities. This study was conducted in order clarify the challenges that Chinese international students experience when they attend an American university with the hope that such challenges can be overcome by the two nations. American universities stand to retain and perhaps build upon both the financial and cultural contribution that Chinese international students make to universities and university communities, while Chinese society may gain more motivated, skilled workers who can successfully take the learning from an American university and creatively apply it to address the needs and challenges of Chinese society.

\section{Chinese international student challenges Language}

Being able to speak and write American English is a critical skill necessary for academic and social success in American universities and, therefore, is a top priority in efforts to prepare Chinese students who plan to attend American universities. A great deal of the literature on this topic stresses that English language proficiency is vital to the success of international students in American higher education because both the academic and social adjustment of international students require a high level of English language skills (Andrade 2006; Yeh and Inose 2003; Sawir 2005). Yeh and Inose (2003) reported that the single greatest challenge experienced by international students is a lack of English proficiency.

In China, American English has gained huge popularity that has led to a growing number of language schools in China and a large number of Internet sites for learning English (Kettle et al. 2012). English language education has become one of the elements that schools in China are evaluated on (Jie and Xiaoqing 2006). Many high school student organizations in China have English corners to help students practice this foreign language (Gao 2012). Many Chinese cities even have 
international schools and programs dedicated to the preparation of students to attend American schools (Robinson and Guan 2012). Thus, Chinese students in general have received a certain level of language training before they go abroad which is beneficial for their education in America, however, these efforts do not appear to be sufficient.

In terms of factors accounting for language difficulties of Chinese students, Wang (2003) identified four key challenges in Chinese usage of English. These included (1) the influence of the Chinese language where "Chinglish" expressions are frequently used, (2) the lack of contextual knowledge or cultural background, (3) the lack of language training, and (4) lack of opportunity to practice English. The language training most Chinese students had received often failed to adequately help them to meet the academic demands of their programs. Furthermore, many Chinese students choose to hang out with other Chinese students instead of host nationals, which further hindered their language improvement.

Researchers have also identified that listening is of the most frequently needed language skills (Liu et al. 2014; Jinyan 2005). The lack of listening skills in the classroom impedes the mastery of a language and plays an overwhelming role in an individual's academic success, more than reading and writing skills or academic aptitude (Abelmann and Kang 2014; Bartlett and Fischer 2011; Fischer 2012; Tweed and Lehman 2002). Smith (2007) suggested that due to cultural and language barriers, international students in American higher education, especially students from China, face hurdles in order to achieve overall academic success.

\section{Emotional issues}

Building upon the difficulty of communicating in English, Chinese international students face emotional issues such as loneliness and stress (Fischer 2012; McClure 2007). Such loneliness or stress is derived from not only the lack of familiar cultural and linguistic environments, but also the missing presence of familiar friends and social networks (Fischer 2012; McClure 2007; Sawir et al. 2008; Zhao et al. 2008; Ip et al. 2009). Fischer (2012) and Gareis (2012) found that international students from East Asia, particularly from China, are inclined to have no American friends or fewer connections with American counterparts, and are normally dissatisfied with the quality of their friendships with American peers. American peers pretend to welcome them, but they did not actually connect with Chinese international students, according to Bartlett \& Fischer (2011). Additionally, Bartlett and Fischer (2011) cited an undergraduate advisor at the University of Delaware as saying, "Chinese students stuck together because they wouldn't necessarily get the warmest reception from the American peers" (p. 5). Chinese students also perceived a lack of support from professors in America, citing such examples as professors ignoring Chinese students' questions and only responding to American students or Chinese students given the cold shoulder while working on a group project. A large array of findings demonstrated that international students who succeed in their new environment heavily rely on both social support and social connectedness (Sherry et al. 2010; Suido et al. 2008). So it is safe to claim that the establishment of social supports and emotional connections is a primary indication of Chinese international students' academic success. 


\section{American classroom structure}

Encountering classroom difficulties is a common phenomenon for Chinese international students in American higher education because of the structure of the lectures (Bartlett and Fischer 2011; Tweed and Lehman 2002; Wang 2013). Bartlett and Fischer (2011) claimed that Chinese international students are familiar with text-based lectures that are different to the lecture style adopted by many American professors. In addition, Tweed and Lehman (2002) suggested that American classrooms were interaction-oriented, and American professors valued questioning, discussion, and group work which all focused on student participation. This active engagement and participation contradicted Chinese students' understanding of English academic lectures where they expected to be passive observers rather than being required to be active participants (Tweed and Lehman 2002). This phenomenon is consistent with the findings from Holmes (2004) that Chinese MBA students in American business schools had poor performance in a Western academic setting and were generally struggling with the interactive nature of classroom communication.

A research from Jinyan (2005) reaffirmed that Chinese international students had difficulty in American university classes because of lecture organization, the lack of use of textbooks, lack of notes written on the board, lack of lecture summary, amount of required student participation, and required group work which were all dissimilar to the format of learning these students were familiar with in China. Jinyan did find that Chinese international students had less difficulty in science and mathematics classes because the concepts and formulas were universal, whereas social science and arts classes were more difficult for Chinese international students because the concepts were completely unique. Further complicating Chinese students' experiences at American universities were the plethora of choices regarding program selection and class selection within programs that were explicitly laid out in China (Yan and Berliner 2009).

While past research has identified numerous challenges that Chinese international students have faced while attending American institutions of higher education, no study has attempted to truly capture the voice of the students and trace the roots of the challenges back to the students' preparation in China. This qualitative study gathered the perspectives of Chinese international students as to the challenges that they felt impeded their academic success and also gathered the perspectives of Chinese international school principals as to how these challenges either are or can be addressed in students' preparation before they attend an American university or college.

\section{Methods}

A qualitative study to explore the phenomenon of difficulties faced by Chinese international students currently attending an American university or college was conducted. The two-phase study first gathered the perspectives of Chinese international students attending an American institution of higher education and then asked principal of Chinese international high schools who prepare students explicitly for international higher educations to explain how the difficulties identified through the student interviews have been or could be addressed. The research question guiding this study was, "What challenges do Chinese students currently attending American universities face during their experience abroad?" 
Possible participants were contacted through random sampling and then purposefully selected to represent a wide variety of locations and institutions. With the assistance of Chinese Student Associations from the American cities with high Chinese international students population, the author randomly invited Chinese international students currently matriculated in American higher education. Participants were then selected from a variety of locations and from a distribution of universities ranked from 50 to 250 by US News \& World Report and more purportedly selective universities ranked from 20 to 50 (USNEWS 2015).

A sampling of 164 Chinese international students who met the criteria of currently attending an American university or college and had attended an international high school in China were included in this study. Average high school Grade Point Average (GPA) for students in the study who were attending a state college or university was $3.18(\mathrm{SD}=0.4)$, while that of participants who were from higher-ranking schools was 3.69 (SD = 0.2). Similarly, participants' average TOEFL score from higher-ranking schools was $104(\mathrm{SD}=4.1)$, which is higher than that of participants from state colleges or universities (Average $=83, \mathrm{SD}=10.2$ ). These phenomena are congruent with the fact that higher-ranking schools expect higher students' academic achievements in the admission processes.

The average time for participants spent in American schools had less discrepancy between the two groups of participants: 1.6 years $(\mathrm{SD}=0.6$ year) for state college or university students and 1.4 years $(\mathrm{SD}=0.9$ year) for students attending higher-ranked schools. The longer students were attending a university or school in America, the greater the potential for students' GPA to reflect academic success or difficulty. The self-reported GPAs were $3.6(\mathrm{SD}=0.18)$ for students from higher-ranking schools and 3.4 ( $\mathrm{SD}=0.6)$ for those students from state colleges or universities. These different academic achievements reflect the theory that education is sequential, and current performance is largely influenced by previous capacity (Moller et al. 2011). In this case, participants who went to higherranking schools had higher high school GPAs and TOEFL scores than their counterparts who went to lower-ranked state colleges or universities.

After basic academic information discussed above was determined, students were interviewed using open-ended questions. Recordings of the interviews were transcribed and coded using open and axial coding. The author formulated the axial codes into different themes to answer the research question. In addition, the author interviewed 47 Chinese international high school principals with the assistance of the Chinese Ministry of Education. Principals were interviewed using open-ended questions relating to the themes identified through the student interview data. These interviews were transcribed, coded, and analyzed.

The process of analysis was iterative and involved both deductive and inductive strategies. Once preliminary descriptions and themes were constructed, the author re-approached selected participants to validate if the themes reflected their original ideas. Member checking crossed locations and campuses. The results indicate a high level of consistency in participants' perceptions from different school types, i.e. between higher and lower ranking universities included in USNEWS (2015) educational rankings. Overall, 228 significant statements and phrases were coded from the 58 transcripts. These excerpts were then axial coded and collapsed into major themes. 
In this study, methodological rigor was attained through verification (Meadows and Morse 2001). Verification is the first step in achieving trustworthiness of a research study. Using the protocols from Frankel (1999) and Meadows and Morse (2001), verification of this study was fulfilled through a review of existing relevant literature, strict adherence to the phenomenological method, bracketing of past experiences, proper documentation of observations and field notes, collection of appropriate data samples, identification of negative cases, and saturation of interview data. Trustworthiness of the study was established using within-project evaluation and was accomplished by multiple methods of data collection (interviews and document analysis), iterative data analysis and coding, member checks of themes with several participants.

The various phases of the study helped to create multiple viewpoints on the topic across issues relating to Chinese students' challenges in American universities and colleges and potential explanations of the problem within American and Chinese school settings. The combination of perspectives of both the students confronting the challenges at American universities and the principals of schools in China dedicated to preparing these students for success at American universities yielded a richness of data not found in prior research. The insights from both perspectives shed light on what has and can be done to support Chinese international student success in American higher education and can be used by Chinese educational leaders to enhance future.

\section{Results}

According to the student participants, the Chinese international preparation programs failed to fully support them in response to the different challenges in American higher education, because of lacking American curriculum, American instructional settings, American educators and so forth. The Chinese international programs generally emphasize test scores rather than language skills or classroom participation. Chinese international students might have high scores in standardized tests, but their language training outcomes were not aligned with American academic expectations. Specifically, student participants across university rankings and locations identified three main types of challenges that they felt impeded their academic success. These themes included language issues, emotional issues, and differences in pedagogy at American universities. The theme of language was the most overwhelmingly dominant theme, impacting the two other themes as well.

\section{Language issues}

The negative consequences of not being proficient in English were the most pervasive challenge for the Chinese international students in the study. Responding quickly and spontaneously, the language barrier was described as "a big trouble for understanding courses," "struggling in every single day throughout classroom," and "my professor said my writing is not a college-level work." The sense of not being able to perform academically was evident in descriptions of miscommunication as "when we have group discussion, I have problem to understand my classmate, and vice versa." Another student explained, "I can only use very little words to express my ideas and people often don't understand my ideas."

A sense of emotional devastation in school performance due to poor language skills was reflected by one male student's explanation. He said: 
Because I cannot understand all the course materials, I have to take notes in class. But when taking notes, the professor has moved on, and I didn't jot down too much information yet. That is the dilemma I have every day. It makes me want to cry.

Similar ideas were reported from another female student, who has spent three years at a prestigious American university:

All my friends [American students] can fully understand the language, but I have to spend much more time to figure out the course after class due to the language barrier. I was not a slow learner in China, and this process makes me doubt my intelligence.

Another female Chinese student added that:

Although my TOEFL and SAT scores are one of the best scores in class, I cannot compete with those who are born naturally. They can speak and write naturally, but I'm very self-conscious about what I say and what I write. I don't want to look bad in the classroom, because everyone is 'genius' to enter this school.

Every student in the study ranked the lack of language proficiency as the most significant challenge they faced that inhibited their academic success. Participants from both higher-ranking schools and regular state colleges or universities unanimously reported that limited language skills compromised their performance in school, and, if greater language proficiency was acquired, they felt that they would be able to outperform the current academic achievements.

\section{Emotional issues}

Impacted by the inability to fully communicate with both peers and professors, participants attending higher-ranking universities particularly noted the impact of both language and cultural factors on their ability to interact with American peers in an emotionally fulfilling manner. One male student from a prestigious California school described his cultural difficulty as:

I'm pretty confident in my language skills before I come here. Not only I have high TOEFL scores, but also I can understand American TV shows pretty well. But when I really walk in to a conversation with my friends here, sometimes I can't understand the culture and background that students speak. For instance, Supreme Court cases and racial conflicts. So, I cannot have deeper dialog with my friends, and currently we just talk about assignment and course works. This can make me feel bad about myself.

With the impediment of cultural barriers added to communication difficulties, making friends after class became an issue, setting a chain of events in motion. A female student who has been in America for two years stated:

I can't join American student's conversation since I can't understand slangs and jargon. So, I can't improve oral English a lot. But this is not too bad for me. Some other Chinese students told me that they are very lonely because they don't have friends here, because they don't know what to talk to their American classmates. All 
the things added up can negatively impact people's scores. I know one people who cannot have friends in school and go back home.

In addition, participants felt that differences in political and religious views made it more difficult to maintain friendships. One student shared the following statement:

My American friends always asked me a lot of political questions. Obviously they are not fully agreeing with my country's political system. But I don't think it's a big problem for people to hang out and make friends. In China, none person I know of cannot hang out due to the politics. We just don't get into those things. Another thing is that, once you said no to a Bible study, people will get upset, and they will not help you and talk to you as they used to be, which is very frustrating.

Acculturation difficulty was also detected from other responses. Some participants claimed that one major cultural difficulty is food. One participant from California summed this up by saying, "I do not know how to order food and not get used to the American food. School is stressful, but thinking about going home after school to eat no Chinese food makes me depressed even more." Similarly, another student wondered, "Why schools don't open an Asian food section in dining hall? We have 3000 Chinese students on campus." The lacks of the familiar, whether it was food, common political or religious views, or vernacular expressions, were noted by participants as having an emotional impact upon them. Such negative emotional feelings can lead to negative academic behaviors including dropping out.

\section{American pedagogy}

Instructional practices found in American university and college classrooms were identified by the participants of this study as another barrier to their academic success. The lack of English language proficiency also was intertwined with this theme as students explained that the emphasis on active participation in American classes troubled them as they had to take more time to plan what they might say or feared not being able to speak well. One student explained, "The most challenge here for me is the English speaking, while doing class presentations and projects."

A sophomore student explained his disappointment with his classroom performance as follows:

We don't have much class activities in China. But here, I need to take notes of my classmates, while thinking what I should say. It's so hard for me. I don't have many training of this type of class before. You know how intimidating to speak when everybody was watching you, plus their English is much better than you.

Similarly, a freshmen student complained that:

I cannot fully understand the class yet. How can people expect the performance in pop quiz? I need time to absorb the content after class in order to comprehend, so in class quiz testing, the same class, learning content is absolutely disaster for me. Right now, my quiz scores are extremely low. And this is a very common problem in my friends' circle. We don't have quiz in China. 
A student attending a top-ranking university in California also discussed the lack of classroom activities in China as compared to American classrooms. She explained, "Nobody will think you are an international student, and you don't expect people [professors and classmates] would cut some slack for you in classroom. You need to do presentation, group discussions, and face-to-face discussions with your professor. Those activities are not the priorities in China. I don't think I do well in those activities.

While text-guided lectures were the reported norm in Chinese classes that participants had always experienced prior to coming to American, the students in this study found American pedagogy to include a much wider variety of activities, with an emphasis on interactivity not found in Chinese schools. One female student described her experience of American classrooms as exactly the opposite of Chinese classrooms. She described American classrooms as extremely lively, interactive, and engaging students in the process of learning. She also commented that "people can stop the professor anytime if they disagree," which is not something done in Chinese classrooms. Combined with language difficulties that required more time for students to process English used in academic settings, more time for students to formulate English responses, and a general fear of not communicating clearly, the high level of interactivity and active participation required in American university and college classes was extremely difficult for Chinese international students to adapt to in order to demonstrate learning and achieve academic success.

\section{Chinese international high school principals perspectives}

The responses of the Chinese international school principals in this study acknowledged that Chinese international students face challenges when they study in America. It was also discussed by each principal how his or her school attempted to prepare Chinese students to study in America. In addition to providing English language classes, more than half of the principals specifically discussed that they utilize American curriculum. Curriculum is content, however, rather than pedagogy, and many of the principals also discussed that Chinese international students have difficulty with the American "ways of learning" or "ways of teaching." Eighty percent of the principals in the study also emphasized that more work needs to be done at their schools to prepare Chinese international students to better understand and speak the English language, as well as a greater understanding of American culture.

The principals interviewed in this study believed that language and culture are keys to success, because language and culture barriers can cause tremendous emotional stress on students and in turn impair students' academic performance. Many of the Chinese principals also suggested that intensive English programs or short-term summer exchange programs are key elements that may better prepare students who plan to attend American colleges and universities. Their responses seemed to imply that is would be very difficult for Chinese educators to "teach" American culture to future Chinese international students.

The principals in this study reported very limited and informal data gathering efforts on the parts of their schools to obtain feedback from graduates regarding satisfaction or dissatisfaction with their high school preparation programs. While which schools graduates were attending in American were tracked by a few of the principal's schools, 
student success in terms of graduation, GPA, or positions obtained after graduating from an American university or college was not tracked. Perceptions of Chinese international student challenges were thus based on personal anecdotes or experiences and media reports.

\section{Discussion}

The study extended previous findings by consolidating challenges and barriers that Chinese international students confronted in American higher education institutions. All the influential factors, such as different classroom structures (Bartlett and Fischer 2011; Tweed and Lehman 2002; Wang 2013), self-segregation (Fischer 2012; Gareis 2012), cultural barriers, alienation and homesickness, and lack of social supports (Sherry et al. 2010; Suido et al. 2008; McClure 2007), stem from language proficiency barriers. International students need proper language skills to communicate inside and outside the classroom for academic activities and casual interactions. Responses of participants such as "test-oriented preparation impaired the real language training," "self-conscious to speak in public," "poor language skills to complete school assignments" and so forth collectively portrayed an array of events with logical connections. Language proficiency impedes school performance that attenuates individual's confidence in social communication. In this regard, fewer social bonds were built causing self-segregation. The lack of a social network diminished support from peers and opportunities to both practice and increase verbal fluency in English and to discuss academic content in greater depth. This lack of a social network then can lead to deteriorated performance in school. Once dropped into this situation, it becomes a vicious circle and makes it increasingly difficult for Chinese international students to "survive" let alone thrive in American colleges and universities.

In order to increase Chinese international student academic success at American universities and colleges, efforts will be needed by both Chinese educational leaders preparing these student prior to their arrival in American and American university leaders who hope to continue to reap both the monetary and cultural benefits that these students bring with them. Recommendations for Chinese education policy, Chinese international schools preparing students to study in America, and American universities and colleges include the following based on the responses of participants in this study:

- Although Chinese international schools have been trying to promote American instruction in Chinese classroom, student participants' feedback indicated that the there is a potential gap in improving the overall quality of Chinese international preparation program. In order help Chinese students mitigate the difficulties to adapt American instructional settings, Chinese international high schools could benefit from inviting American colleagues to visit Chinese schools and help Chinese educators to implement course designs. In the same vein, education policy could actively encourage and assist educators to obtain degrees in teaching at American universities and colleges or observe classes in American higher education as visiting scholars (Leutwyler and Meierhans 2016). This policy has been demonstrated highly effective in other countries that could offer valuable implication for Chinese international education. The author believes that these implications would help 
Chinese educators in international schools to have a knowledgeable supply of using instructional techniques such as group discussions, group projects, quizzes, and class presentations so that Chinese students attending these international schools may prepare their learning in response to such classroom structures found in American schools.

- Chinese international schools also could hire qualified American educators to replicate American pedagogy in Chinese international school classrooms while cadres of American-trained Chinese educators are being developed. Although many Chinese international schools currently have American educators and intend to put more American staff in the classroom, the overall quality of the American crew may remain questionable and need an overhaul. The responses from student participants from this study indicated that many American educators in Chinese international may lack professional and instructional skills to deliver an appropriate class or may not have undergone rigorous teacher preparation in the US before. Hence, the author suggests that the hiring process needs to meet strict standards and ensure that the hired American educators hold proper qualification or certification that can fulfill the role of a teacher in the classroom.

- Chinese international schools could provide opportunities for students to experience American culture and gain proficiency in English by setting up summer or semester-long exchange programs in partnership with reputable American high schools. The author is cognizant that there have been many similar programs currently administered in Chinese international schools, but previous researchers have critiqued the effectiveness of these programs which are considered as a tourism trip and running by money-driven agents (Lesch et al. 2014). Under the circumstance, the author suggests that the operation of exchange program for international preparation program needs to avoid potential misconducts in practice and requires purposeful design in order to fulfill the initiatives of the program and align with the real needs of Chinese international students.

- Chinese international schools could also require that students take an online class from an American institution of higher education as another means to familiarize students with American expectations of participation and assessment, as well as encourage written and oral English language practice.

- Chinese international schools could also develop and require that students take a class or classes specifically aimed at preparing them for attendance at an American university. Such courses should include knowledge of American school settings, course arrangement, testing formats, and appropriate classroom participation, according to the participants in this study.

- American universities and colleges should ensure that Chinese international students are provided with directions to the university or college prior to their arrival in the States. As one freshman in this study noted, "You don't want to figure out how to go to your school when you landed at the airport. It's so frustrating if you did not how to get to your school."

- American universities and colleges should be sure that housing details are communicated as early as possible prior to the arrival of Chinese international students on campus. Another participant in the study highlighted this desire for information by explain, "You want to find out everything for your future 
life. For instance, after you book your school housing, making sure asking them the steps for checking in. Carrying 80 pounds of luggage while finding your manager is not a fun thing to do."

- American universities and colleges should also provide prospective students with information about climate, demographic reports, dining, and transportation. Videos explaining such elements would be a cost-effective way of providing Chinese international students with information that they can use to navigate campus life thus reduce their stress levels in the transition from their homeland to American higher education. Such information regarding how to register, how to check in to housing, and other such details would also reduce the anxiety of parents of these students, as well.

- American universities and colleges should offer English tutoring to increase verbal skills and fluency of Chinese international students and also writing lab supports to increase written fluency. As noted throughout the research and in the responses of participants in this study, language fluency is a critical component of a student's ability to achieve success at an American university.

- American universities and colleges should actively encourage and support a buddy or ambassador program where international students are paired with a reliable American peer who has been at the university and is experiencing success for at least one academic year in order to provide an initial social support. Such American peers can also encourage international students to become involved in extracurricular clubs and hobby organizations in order to enlarge Chinese international students' social networks.

- International clubs at American universities and colleges that include both American and international students in social settings could also be another venue to break down the isolation, self-segregation, and loneliness of all international students.

- Instructors in American universities and colleges should also be encouraged to explicitly recognize the language difficulties that international students experience and openly address such concerns with students. Instructors can also encourage international students to continually practice their English language skills through constant practice of their verbal and reading skills through academic materials and experiences and informal social venues.

\section{Conclusions}

Findings from this study, as well as past research, suggest the need for additional studies to track Chinese international student progress and further identify supports that may increase their academic success at American universities and colleges. Such studies should include advice from Chinese international students who have successfully completed American degrees and obtained desirable job positions following graduation, as well as interviews with Chinese international students who have dropped out of American degree programs to determine what supports they feel would have enabled them to complete their degrees.

Informed by the voices and experiences of the Chinese international students who participated in this study, it is hoped that the recommendations made to increase Chinese international student success in American institutions of higher education can serve as useful starting points to ensure that there is a continued level of interest among Chinese students to study in America in the future. It is beneficial 
to both countries for Chinese students to study in America. As Chinese students gain knowledge and build social networks internationally, American peers who attend universities and colleges with Chinese international students are also enriched by the cultural knowledge gained from working with and being friends with someone from another nation. It is also hoped that the increased sharing of knowledge across international boundaries will enable student from both nations to more creatively solve problems faced by their home nations and globally, an outcome that would indeed benefit all mankind.

Author's information

Dongfang Liu

Research assistant

University of Northern Colorado

Professional Highlights: A former principal at the high school level where he implemented several workshops for social learning community and developed national-wide training for the supervision of certified staff. He has worked with large urban districts on building internal leadership capacity and minority leader recruitment through the Education Bureau of Chongqing for Leadership project. Mr. Liu has conducted research on educational policy implementation, standards-based assessment, school finance, international education, and low SES students' school success.

\section{Competing interests}

The author declares that he has no competing interests.

Received: 3 May 2016 Accepted: 13 August 2016

Published online: 18 August 2016

\section{References}

Abelmann, N., \& Kang, J. (2014). A Fraught Exchange? U.S. media on Chinese international undergraduates and the American. University Journal of Studies in International Education, 18(4), 382-397.

Andrade, M. S. (2006). International students in English-speaking universities: Adjustment factors. Journal of Research in International Education, 5(2), 131-154.

Bartlett, T., \& Fischer, K. (2011). The China Conundrum. The New York Times. Retrieved from http://www.nytimes.com/ 2011/11/06/education/edlife/the-china-conundrum.html?_r=0. Accessed 1 Dec 2015.

Chu, T. (2004). 150 Years of Chinese Students in America. Harvard China Review, 5(1), 7-2.

Fischer, K. (2012). Many foreign students find themselves friendless in the U.S., study finds. The Chronicle of Higher Education. Retrieved from http://www.lexisnexis.com/hottopics/lnacademic/. Accessed 1 Dec 2015.

Fischer, K. (2014). For Some Foreign Students, U.S. Education is losing its attraction. New York Times. Retrieved from http://www.nytimes.com/2014/05/26/world/asia/for-some-foreign-students-us-education-is-losing-its-attraction. html?_r=0. Accessed 1 Dec 2015.

FlorCruz, M. (2013). 1 In 4 Chinese students drop out of ivy universities and return home for jobs. International Business Times. Retrieved from http://www.ibtimes.com/1-4-chinese-students-drop-out-ivy-universities-return-home-jobs1446382. Accessed 1 Dec 2015.

Frankel, R. M. (1999). Standards of qualitative research. In B. F. Crabtree \& W. L. Miller (Eds.), Doing qualitative research (2nd ed., pp. 333-346). Thousand Oaks: Sage.

Gao, S. (2012). The biggest English corner in china. English Today, 28(3), 34-39. doi:10.1017/S0266078412000296.

Gareis, E. (2012). Intercultural friendship: Effects of home and host region. Journal of International and Intercultural Communication, 5, 309-328.

Harris, D. (2012). Chinese students in America. It's bad out there. China Low Blog. Retrieved from http://www. chinalawblog.com/2012/01/chinese_students_in_america_why_do_they_even_bother.html. Accessed 1 Dec 2015.

Holmes, P. (2004). Negotiating differences in learning and intercultural communication: Ethnic Chinese students in a New Zealand University. Business Communication Quarterly, 67, 294-307.

Ip, D., Chui, E., \& Johnson, H. (2009). Learning experiences and outcomes of culturally and linguistically diverse students at The University of Queensland: A preliminary study. Brisbane: School of Social Science, The University of Queensland.

Jie, L., \& Xiaoqing, Q. (2006). Language learning styles and learning strategies of tertiary-level English learners in china. Regional Language Centre Journal, 37(1), 67-90. doi:10.1177/0033688206063475.

Jinyan, H. (2005). Challenges of Academic Listening in English: Reports by Chinese Students. College Student Journal, 39(3), 553-569.

Kaufman, J. (2004). The Interplay between social and cultural determinants of school effort and success: an investigation of Chinese-immigrant and second-generation Chinese students' perceptions toward school. Social Science Quarterly, 85(5), 1275-1298.

Kettle, M., Yuan, Y., Luke, A., Ewing, R., \& Shen, H. (2012). The pedagogical, linguistic, and content features of popular English language learning websites in china: A framework for analysis and design. Frontiers of Education in China, 7(4), 534.

Lesch, A., Pisano, J., \& Kapila, Y. L. (2014). The student perspective: International exchange programs. The Journal of the Michigan Dental Association, 96(6), 33

Leutwyler, B., \& Meierhans, C. (2016). Effects of international student exchange on pre-service teachers: A quasi-experimental study. Intercultural Education, 1, 20. doi:10.1080/14675986.2016.1144713. 
Liu, S. (2013). Chinese students are dropping out of school in US. Sino-US. Retrieved from http://www.sino-us.com/292/ Chinese-students-are-dropping-out-of-school-in-US.html. Accessed 1 Dec 2015.

Liu, D., Brancato, V., \& Da, F. (2014). International high school development in Chongqing: test preparation vs. university preparation. ICEMSS, 14, 48-52. doi:10.2991/icemss-14.2014.14.

Luo, C. (2013). One in four Chinese students drop out of Ivy League schools. South China Morning Post. Retrieved from http:// www.scmp.com/news/china-insider/article/1342846/study-one-four-chinese-students-drop-out-ivy-league-schools. Accessed 1 Dec 2015.

McClure, J. W. (2007). International graduates' cross-cultural adjustment: Experiences, coping strategies, and suggested programmatic responses. Teaching in Higher Education, 12(2), 199-217.

Meadows, L. M., \& Morse, J. M. (2001). Constructing evidence within the qualitative project. In J. M. Morse, J. M. Swansen, \& A. Kuzel (Eds.), Nature of qualitative evidence (pp. 187-200). Thousand Oaks: Sage.

Moller, S., Stearns, E., Potochnick, S. R., \& Southworth, S. (2011). Student Achievement and College Selectivity: How Changes in Achievement During High School Affect the Selectivity of College Attended. Youth \& Society, 43(2), 656-680. doi:10.1177/0044118X10365629.

Robinson, J., \& Guan, X. (2012). The changing face of international education in china. On the Horizon, 20(4), 305-312. doi:10.1108/10748121211272443.

Ruiz, N. G. (2014). The geography of foreign students in U.S. higher education: origins and destinations. Brookings. Retrieved from http://www.brookings.edu/research/interactives/2014/geography-of-foreign-students\#/M10420. Accessed 1 Dec 2015.

Ruiz, N. G. (2013). Immigration facts on foreign students. Brookings. Retrieved from http://www.brookings.edu/research/ interactives/2013/facts-on-foreign-students. Accessed 1 Dec 2015.

Sawir, E. (2005). Language difficulties of international students in Australia: The effects of prior learning experience. International Education Journal, 6(5), 567-580.

Sawir, E., Marginson, S., Deumert, A., Nyland, C., \& Ramia, G. (2008). Loneliness and international students: An Australian study. Journal of Studies in International Education, 12(2), 148-180.

Sherry, M., Thomas, P., \& Chui, W. (2010). International Students: A vulnerable student population. Higher Education, $60(1), 33-46$.

Siu, S. (1994). Taking no chances: A profile of a Chinese-American family's support for school success. Equity and Choice, $10(2), 23-32$.

Smith, L. (2007). Foreign Students Still Face Hurdles. Chronicle of Higher Education, 53(45), 31-41.

Suido, S. M., Shaunessy, E., Michalowski, J., \& Shaffer, E. S. (2008). Coping strategies of high school students in an International Baccalaureate program. Psychology in the Schools, 45, 960-977.

Tweed, R. G., \& Lehman, D. R. (2002). Learning considered within a cultural context. American Psychologist, 57(2), 89-99.

USNEWS. (2015). National Universities Rankings. Retrieved from http://colleges.usnews.rankingsandreviews.com/bestcolleges/rankings/national-universities?int=9ff208. Accessed 1 Dec 2015.

Wang, Y. (2003). The contextual knowledge of language and culture in education: Exploring the American university experiences of Chinese graduate students. (Doctoral dissertation). Retrieved from http://aquila.usm.edu/theses dissertations/2631/

Wang, L. (2013). Going global: The changing strategy of internationalisation of education in China. Journal of Higher Education Policy and Management, 35(3), 305-315.

Yan, K., \& Berliner, D. (2009). Chinese international student's academic stressors in the United States. College Student Journal, 43(4), 939-960.

Yeh, C. J., \& Inose, M. (2003). International students' reported English fluency, social support satisfaction, and social connectedness as predictors of acculturative stress. Counselling Psychology Quarterly, 16(1), 15-28.

Zhao, E. (2013). Chinese students struggle for returns on education in U.S. Wall Street Journal. Retrieved from http:// blogs.wsj.com/chinarealtime/2013/03/27/chinese-students-struggle-for-returns-on-education-in-u. Accessed 1 Dec 2015.

Zhao, Y., Jindal-Snape, D., Topping, K., \& Todman, J. (2008). Theoretical models of culture shock and adaptation in international students in higher education. Studies in Higher Education, 33(1), 63-75.

Zhou, Z., Peverly, S. T., Xin, T., Huang, A. S., \& Wang, W. (2003). School adjustment of first-generation Chinese-American adolescents. Psychology in the Schools, 40(1), 71-84. Retrieved from http://onlinelibrary.wiley.com/doi/10.1002/pits. 10070/abstract

\section{Submit your manuscript to a SpringerOpen ${ }^{\circ}$ journal and benefit from:}

- Convenient online submission

- Rigorous peer review

- Immediate publication on acceptance

- Open access: articles freely available online

- High visibility within the field

- Retaining the copyright to your article

Submit your next manuscript at $\boldsymbol{~ s p r i n g e r o p e n . c o m ~}$ 